\title{
La urbanización en la periferia sur poniente de Santiago de Chile. Poblaciones, servicios y política habitacional en Chuchunco (1920-1933) ${ }^{1^{*}}$
}

\author{
The urbanization in the south west periphery of Santiago de \\ Chile. Worker's neighborhoods, services and housing policy, \\ Chuchunco (1920-1933).
}

Simón Castillo

Universidad Diego Portales, Chile

ORCID: 0000-0002-8405-7543

Waldo Vila

Universidad de Chile

ORCID: 0000-0001-9669-1472

DOI: $\underline{\text { https://doi.org/10.25032/crh.v7i12.12 }}$

Recibido: $26 / 1 / 2021$

Aceptado: 5/5/2021

Resumen. Este artículo explora el extenso sector de Santiago de Chile ubicado al poniente de la línea del ferrocarril al sur, conocido como Chuchunco. Este margen de la ciudad intensificó su trama de forma considerable entre 1920 y 1933, levantándose poblaciones para la clase trabajadora, entre las cuales estuvieron principalmente aquellas vendidas o arrendadas por lotes y algunos conjuntos edificados por el Estado. El objetivo es indagar en una de las zonas más olvidadas por la historiografía urbana sobre la capital, centrándonos en la configuración material de los asentamientos, sus principales dificultades para alcanzar una habitabilidad acorde a las expectativas de sus residentes y la labor fiscal mediante la política de vivienda. La particularidad de esta área radicó en su lejanía de la ciudad consolidada, además de la carencia de servicios e infraestructura, atrasando su desarrollo. Esta pesquisa se realiza mediante la revisión de fuentes oficiales tanto municipales como estatales, además de prensa.

\footnotetext{
$1^{*}$ Este artículo es parte del proyecto Fondecyt de Iniciación $n .^{\circ}$ 11180082, financiado por ANID-Chile y patrocinado por la Universidad Diego Portales, que busca historiar el crecimiento periférico de Santiago y Valparaíso entre 1925 y 1958. Los autores agradecen a la magíster en historia Claudia Deichler por parte de la revisión de fuentes realizada.
} 
Palabras clave: poblaciones autoconstruidas - política de vivienda - Santiago de Chile - urbanización

Abstract. This article explores the Santiago de Chile's territory located to the west of the railway line to the south, known as Chuchunco. This limit of city grew a lot between 1920 and 1933, specially by poblaciones (worker's neighborhoods), sold or leased by lots and some built by the State. The objective is to research one of the areas most forgotten by urban historiography about the capital of Chile, focusing on the material configuration of the settlements, its main difficulties in achieving habitability according to the expectations of its residents and the public policy for low-income residents. The particularity of Chuchunco lay in its remoteness from the consolidated city, plus the lack of services and infrastructure, delaying its development. This research is carried out by reviewing official sources, as well as the press.

Keywords: worker's neighborhoods - housing policy - Santiago of Chile - peripheral urbanization

\section{Introducción}

Desde luego, no debe olvidarse que no todo Santiago está comprendido dentro de los límites administrativos de la comuna urbana. Tenemos a la vista un plano, del cual resulta que los límites abarcan apenas la mitad de la ciudad verdadera. El resto, o sea otra mitad del recinto poblado, queda fuera de los límites y pertenece a las comunas rurales. La mayor parte de los suburbios propiamente tales están en este caso. «Barrios Populares», El Diario Ilustrado [Santiago], may. 16, 1930.

En Chile, la palabra chuchunco en el imaginario popular se entiende como denominación de un territorio lejano y poco accesible. Espacio considerado durante siglos como área rural, su desarrollo urbano comenzó recién hacia finales del siglo XIX, acelerándose desde entonces por medio de diversas urbanizaciones entre las cuales destacaron, a partir de 1920, las denominadas poblaciones. Dicha expresión fue utilizada para designar los asentamientos levantados en las periferias, habitados por estratos bajos y muchas veces originados de manera ilegal. En efecto, en su mayoría eran loteamientos que implicaron la autoconstrucción por parte de los propios adquirentes, en un marco regulatorio débil que no garantizaba la provisión de servicios básicos e infraestructura. La ausencia de las condiciones mínimas de salubridad y la precariedad de las habitaciones terminó configurando - junto con el conventillo- el denominado problema de la vivienda. Este consistió en un diagnóstico y proyecto de intervención en los cuerpos, 
viviendas y modos de habitar de la clase trabajadora, buscando con ello reformar sus hábitos domésticos. Esta intervención estuvo a cargo de una variedad de disciplinas, como la medicina, el derecho, la asistencia social y otras. ${ }^{2}$

Siguiendo estos lineamientos, analizaremos este fenómeno en un periodo de estudio marcado por la presidencia del coronel Carlos Ibáñez del Campo (1927-1931) que, como parte de su proyecto político, llevó adelante una reforma sanitaria y una modernización urbanística de Santiago.3 Ambas políticas respondían a una nueva visión de la labor estatal y fueron representativas de los ideales de cambio social plasmados desde su toma del poder a través una elección donde fue el exclusivo candidato. 4

En efecto, en una coyuntura donde se apelaba a la urgente solución de los problemas sociales o «cuestión social», el principal cambio estaría en el rol entregado al Estado, contrastando con el rol más bien pasivo que había tenido hasta entonces. Se trataría de un actor comprometido con los cambios sociales, por lo que, además de impulsar la economía y el desarrollo social mediante la creación de nuevos organismos como el Banco Central y la Contraloría General de la República - incorporaba la puesta en marcha de las leyes sociales y la urgencia por regenerar la política, sobre todo mediante la inclusión de ingenieros. Una arista crucial de este despliegue fue el énfasis de las autoridades en una visión patriótica, realzando la unidad nacional: se apeló así a una neutralidad en las decisiones de esta nueva tecnocracia, la que se presentaba como apartidista y sin una ideología definida, aunque el anticomunismo fue parte relevante del discurso ibañista. 5 Como veremos, Chuchunco - para entonces un área degradada de la ciudad - fue uno de los sectores incorporados en esta forma de intentar modernizar la periferia, implementando los servicios básicos (electricidad, pavimentación,

\footnotetext{
2 Anahí Ballent y Jorge Francisco Liernur, La casa y la multitud. Vivienda, política y cultura en la Argentina moderna. (Buenos Aires: FCE, 2014), Introducción. Véase también Diego Armus y Juan Suriano, «The Housing Issue in the Historiography of Turn-of-the-Century Buenos Aires», Journal of Urban History. 24 (1998): 416-428.

3 Entenderemos por ciudad de Santiago no solo la comuna homónima, sino también las municipalidades rurales que la rodeaban y que fueron objeto de una intensa urbanización desde comienzos del siglo XX (Conchalí, Providencia, Nuñoa Renca, San Miguel, Yungay y Quinta Normal).

4 Respecto a la trayectoria política del coronel Ibáñez, ver Augusto Varas, "Los militares y la política en Chile: 1810-2015”. Historia Política de Chile, 1810-2010. Tomo I. Iván Jaksic y Juan Luis Ossa, eds., (Santiago de Chile: FCE y U. Adolfo Ibáñez, 2017), 93-94.

5 La puesta en marcha de medidas y entidades para paliar los problemas sociales ha sido abordada recientemente por Julio Pinto, «iLa cuestión social debe terminar! La dictadura de Carlos Ibáñez en clave populista, 1927-1931», Historia. 53 (2021): 591-630. En cuanto al supuesto apoliticismo de esos técnicos, ver Rodrigo Henríquez, En «Estado sólido»: políticas y politización en la construcción estatal. Chile: 19201950. (Santiago de Chile: UC, 2014), 144-147.
} 
alcantarillado, etc.), y construyendo viviendas económicas (Rojas, 1996, 23). Todo esto integró una transformación urbanística general, concentrada en especial en renovar el centro histórico (Cáceres, 1995, 99-108).

Un papel crucial en este proceso cumplió la legislación social, que reguló las relaciones laborales y enfatizó en la higiene pública, desplegándose una ambiciosa política de vivienda, a cargo del recién instituido Ministerio de Bienestar Social. En el ámbito de la habitación, buena parte de las medidas de dicha entidad apuntaron a resolver las demandas del creciente segmento de la población que tenía la posibilidad de acceder a un terreno en propiedad, abandonando así algunos de ellos su condición de inquilinos al interior de los insalubres conventillos, para pasar a levantar modestos ranchos. ${ }^{6}$ A este grupo de compradores a plazo se sumaban aquellos que arrendaban un sitio, conocidos como mejoreros, estando ambos tipos de ocupación del suelo emparentados en la autoconstrucción y su precariedad. De este modo, en la urbanización de Chuchunco convergieron una variedad de actores institucionales y sociales.

Así, el presente artículo busca indagar en una de las zonas más olvidadas por la historiografía urbana sobre la capital chilena, centrándonos en la configuración material de los asentamientos y sus principales dificultades para alcanzar una habitabilidad acorde a las expectativas de sus residentes. Estos anhelos apuntaban a generar en dichos espacios un tipo de habitar que alcanzara un estándar de vida urbano, esto es, similar al existente en el centro y las comunas más consolidadas de la ciudad, para poder así acceder a una diversidad de servicios, comercio, infraestructura pública y equipamiento comunitario (Roncayolo, 1988).

Nuestra hipótesis es que en este periodo se intensificó la ocupación de Chuchunco, pasando de una condición rural a convertirse en una de las periferias más densas y cercanas a la ciudad, marcada por la concentración de la pobreza y las deficiencias en la habitabilidad. Se postula que en este proceso tuvieron una activa labor los arrendatarios a pisos y compradores de lotes que, junto a algunos avances de la política pública de vivienda, propiciaron el acceso a la propiedad de un importante segmento de la población.

\footnotetext{
${ }^{6}$ Sobre este fenómeno a escala subcontinental, ver José Luis Romero, Latinoamérica. Las ciudades y las ideas. (Buenos Aires: Siglo Veintiuno Editores, 2010). Arturo Almandoz, Modernización urbana en América Latina. De las grandes aldeas a las metrópolis masificadas. (Santiago de Chile: Ed. Colección Estudios Urbanos UC, 2013). Para el caso chileno ver Rodrigo Hidalgo, La vivienda social en Chile y la construcción del espacio urbano en el Santiago del siglo XX. (Santiago de Chile: Pontificia Universidad Católica de Chile, Instituto de Geografía / DIBAM, Centro de Investigaciones Diego Barros Arana, 2004). Isabel Torres, «Los conventillos en Santiago (1900-1930)», Cuadernos de Historia. 6 (1986): 67-85.
} 
De esta manera, se plantean los siguientes objetivos: primero, describir la transición en los modos de habitar de los sectores populares santiaguinos; segundo, explorar las repercusiones materiales del proceso de crecimiento periférico y tercero, la implementación de la política pública de vivienda en el sector. El artículo aporta al conocimiento sobre la historia de Santiago en la primera mitad del siglo xx y en particular lo referido a la construcción y expansión de sus márgenes. Así, plantea el habitar como un entramado complejo, vinculando el proceso local de ocupación del suelo con el crecimiento periférico (Martínez, 2020, 5-26).

El fenómeno de la formación de poblaciones periféricas se inserta en una serie de estudios sobre el habitar informal relacionado al crecimiento de las capitales latinoamericanas desde finales del siglo XIX, Río de Janeiro entre ellas (Pereira, 2005), como efecto del progresivo desarrollo de la industrialización y de diversos rubros económicos. Este tipo de espacios se sostuvo en base al mecanismo de renta de la tierra, posibilitando la continua expansión de los suburbios. En Chile, esta última palabra tuvo desde entonces un sentido asociado a las carencias materiales, tanto de infraestructura como servicios. 7 De este modo, se registró una calidad material y de vida disminuida en relación con los barrios consolidados en el centro de la ciudad, constituyendo muchas veces espacios degradados ambiental y socialmente y que evidenciaron las tensiones en el tránsito de lo rural a lo urbano, ambivalencia crucial en la definición de «periferia» (López Trigal, 2010, 288).

En el caso de Chile, este tema ha sido abordado a través de la revisión de la tipología mayoritaria de la época, los conventillos, forma de vivienda colectiva que predominó en Santiago y otras ciudades hasta mediados del siglo xx (Torres, 1986,67-85; Urbina, 2002). Pese a sus valiosas informaciones, estas obras no incorporan a la venta y arriendo de sitios, ya que comenzaron a masificarse recién hacia 1920. A esto se suman investigaciones sobre la política habitacional y sus efectos en la capital, mientras otras han concentrado el foco en la acción política de los habitantes y su relación con el Estado. Precisamente son estas últimas las que más se han acercado a nuestro objeto de estudio; sin embargo, se han ocupado más bien de aspectos políticos y de movimientos sociales o

\footnotetext{
7 Este mecanismo consiste en el uso de la tierra como mercancía, procurando obtener la mayor plusvalía al menor costo de inversión posible. Para más detalles ver a Armando de Ramón, «Estudio de una periferia urbana. Santiago de Chile 1850-1900», Historia. 20 (1985): 199-294. Respecto al suburbio, Gonzalo Cáceres y Francisco Sabatini, «Suburbanización y segregación urbana en el Chile decimonónico: hipótesis sobre la formación histórica del Gran Valparaíso». Historias urbanas. Homenaje a Armando de Ramón. Valenzuela, Jaime, ed. (Santiago de Chile: Ed. Universidad Católica de Chile, 2007), 93-121.
} 
bien de la dimensión legal e institucional en torno a dichos grupos de la población. En este registro, estos enfoques no han priorizado en la formación de periferias urbanas (Hidalgo, cap. 2 a 4; Espinoza, 1987). En este sentido, el único trabajo que se vincula de forma directa con aquel fenómeno en Chuchunco es un artículo de Armando de Ramón (1985), el que no obstante fija su atención en la segunda mitad del siglo XIX. En cuanto a los conjuntos levantados por acción estatal, estos corresponden a los construidos a partir de la Ley de Habitaciones para Obreros de 1906 -la primera iniciativa de este tipo en el país y América Latina- aunque existen investigaciones que exploran el marco general en que se dio desde entonces este tipo de asentamientos, reparando en algunos casos (Hidalgo, cap. 2).

Por su parte, el estudio de este territorio para épocas posteriores se ha enfocado en lo ocurrido con las poblaciones construidas durante la segunda mitad del siglo pasado, como el caso de los conjuntos Robert Kennedy, Santiago y Los Nogales. ${ }^{8}$ Estas publicaciones se han basado preferentemente en historia oral, como una recuperación de la memoria social de los pobladores de segunda y tercera generación. En el caso de Los Nogales, ha sido indagada además desde la historia social, como parte de las primigenias ocupaciones de terrenos o tomas, constituyendo una de las más importantes de Chuchunco (Rojas, 2018, 1-33). A este grupo de obras se suma un libro sobre la Compañía de Gas de Santiago, el que entrega información del Gasómetro San Borja, una de las infraestructuras industriales más antiguas e importantes del sur oriente del barrio (Nazer, 1996, 129-141). En suma, para los objetivos del presente artículo, estos trabajos distan de entregarnos antecedentes referidos a la urbanización desarrollada en las primeras décadas del siglo pasado.

En aquella época, los servicios (pavimentación, electricidad, seguridad pública y condiciones de higiene) eran considerados básicos para el desarrollo de una ciudad moderna y de un modo de vida urbano. Para estudiarlos ahondaremos tanto en la labor de las autoridades como en la de los vecinos afectados, entendiéndolo como un problema que sobrepasaba los límites de Chuchunco (Martínez, 2020). El análisis se sustenta en fuentes de la Intendencia de Santiago y del municipio homónimo, así como de prensa y documentos oficiales, tales como Censos de Población y fuentes del Ministerio de Bienestar Social. A esto se suma la revisión de planos históricos de la capital y la

\footnotetext{
${ }^{8}$ Luis Morales, Voces de Chuchunco. Santiago de Chile: Ed. Centro Esperanza,1989; Daniel Fauré y Cristina Moyano, eds., Memoria social de la población Los Nogales (1947-2015), Santiago de Chile: Usach, 2016; Daniel Fauré, eds., Memoria social de la población Santiago (1966-2017), Santiago de Chile: Usach, 2018.
} 
incorporación de algunas imágenes que forman parte del archivo de la Compañía Chilena de Electricidad (Chilectra), que durante la época cubierta por este artículo amplió el servicio de alumbrado en la zona, realizando un importante registro fotográfico de los trabajos.

\section{El crecimiento urbano al poniente de la Estación Central de Ferrocarriles, 1856-1920}

El estreno de la Estación Central de Ferrocarriles (1856), instalada en el extremo poniente de la Alameda de las Delicias -la principal arteria de la ciudad- comenzó la urbanización del sector sur poniente de Santiago. Fue allí donde se concentró primero y con mayor intensidad el poblamiento del área. 9 Desde entonces, comenzó un lento proceso de incorporación a la trama consolidada, denominándose Chuchunco al extenso barrio emplazado al poniente de dicho terminal. En un principio, concentró actividades fabriles beneficiadas por la existencia del tren, para dar paso luego al loteo de grandes propiedades rurales que desde finales del siglo XIX fueron conformando una creciente periferia urbana. ${ }^{10}$

\footnotetext{
9 Este terminal, el principal de la capital y en servicio hasta el día de hoy, ha generado varias investigaciones, dentro de las más recientes se encuentra Carlos Sottorff, La construcción ferroviaria y la transformación urbana y productiva de Santiago poniente, 1855-1897, Tesis de Doctorado en Historia, Santiago: Universidad de Santiago de Chile, 2019. Francisca. Jürgensen, De capital poscolonial a capital republicana: transformaciones en la arquitectura cívica de Santiago durante el proceso de consolidación de la República, 1840-1879. Tesis de Doctorado en Arquitectura y Estudios Urbanos, Santiago: Pontificia Universidad Católica de Chile, 2012.

${ }^{10}$ De Ramón, «Estudio de una periferia urbana...». Esta incorporación a la ciudad se vio estimulada por la inauguración de la primera línea del Ferrocarril Urbano de Santiago (carros de sangre), que unió la Estación con la Universidad de Chile en 1857.
} 


\section{Figura 1}

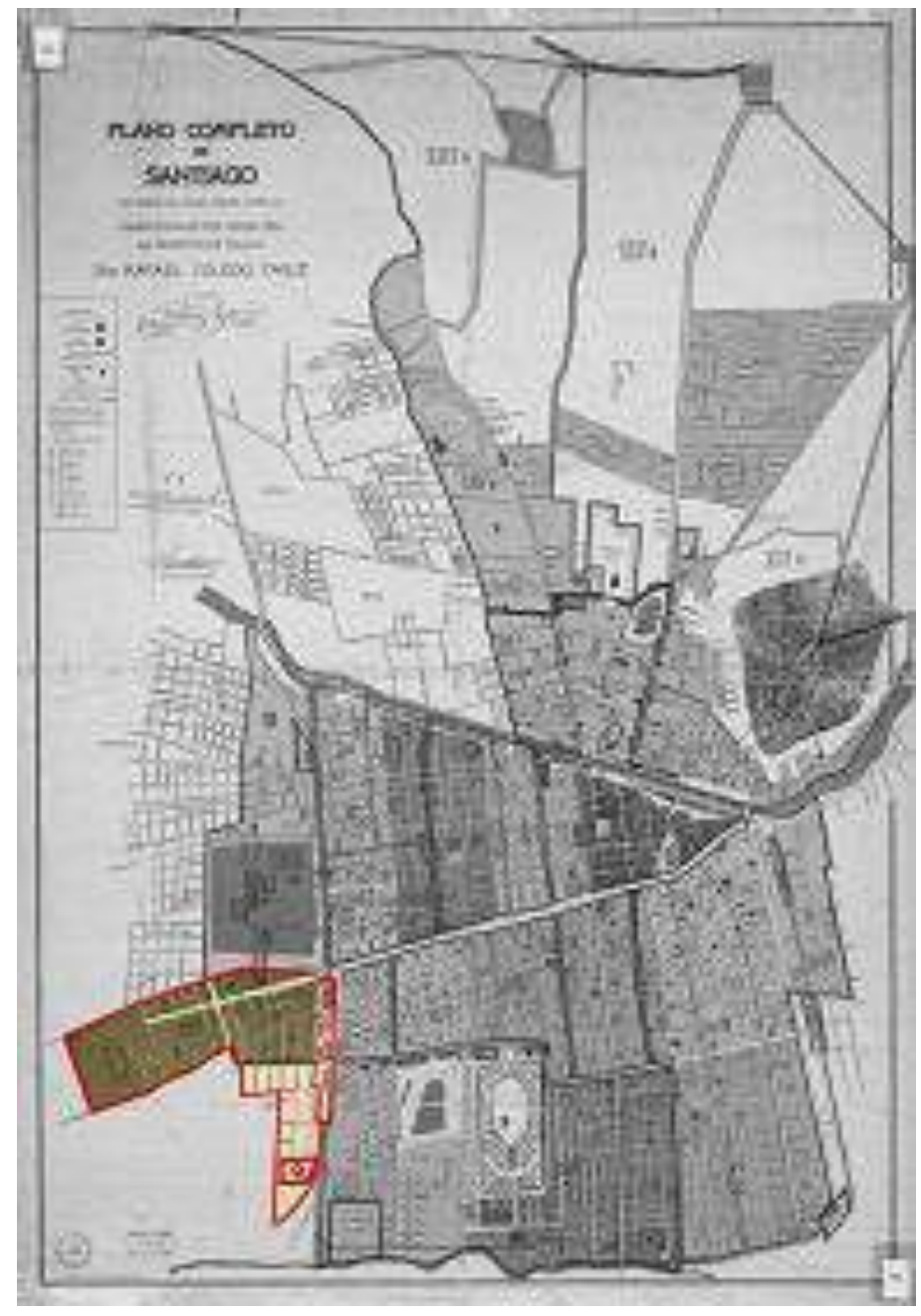

Plano de Chuchunco y su ubicación en Santiago, 1918.

Fuente: Plano completo de Santiago, Imprenta Barcelona, 1930.

Un ejemplo destacado de este proceso fue la población Ruiz Tagle, levantada a fines de la década de 1870 y emplazada en la antigua chacra La Boca de la Cañada, propiedad de dicha familia. Estos terrenos se encontraban al norte de la estación del ferrocarril, ocupando aquellas manzanas que marcaban el final de la Alameda por el poniente y su bifurcación en dos avenidas: Latorre (continuidad de la Alameda) (ver figura 2) y Los Pajaritos (actual Av. Ecuador). Al sur de estas arterias se ubicaban los terrenos de la chacra San José de Chuchunco y sobre la cual se instalarían numerosos asentamientos a partir de la década de $1920 .{ }^{11}$

${ }^{11}$ Respecto a este sector de la ciudad ver de Ramón, «Estudio de una periferia urbana...», 287. 


\section{Figura 2.}

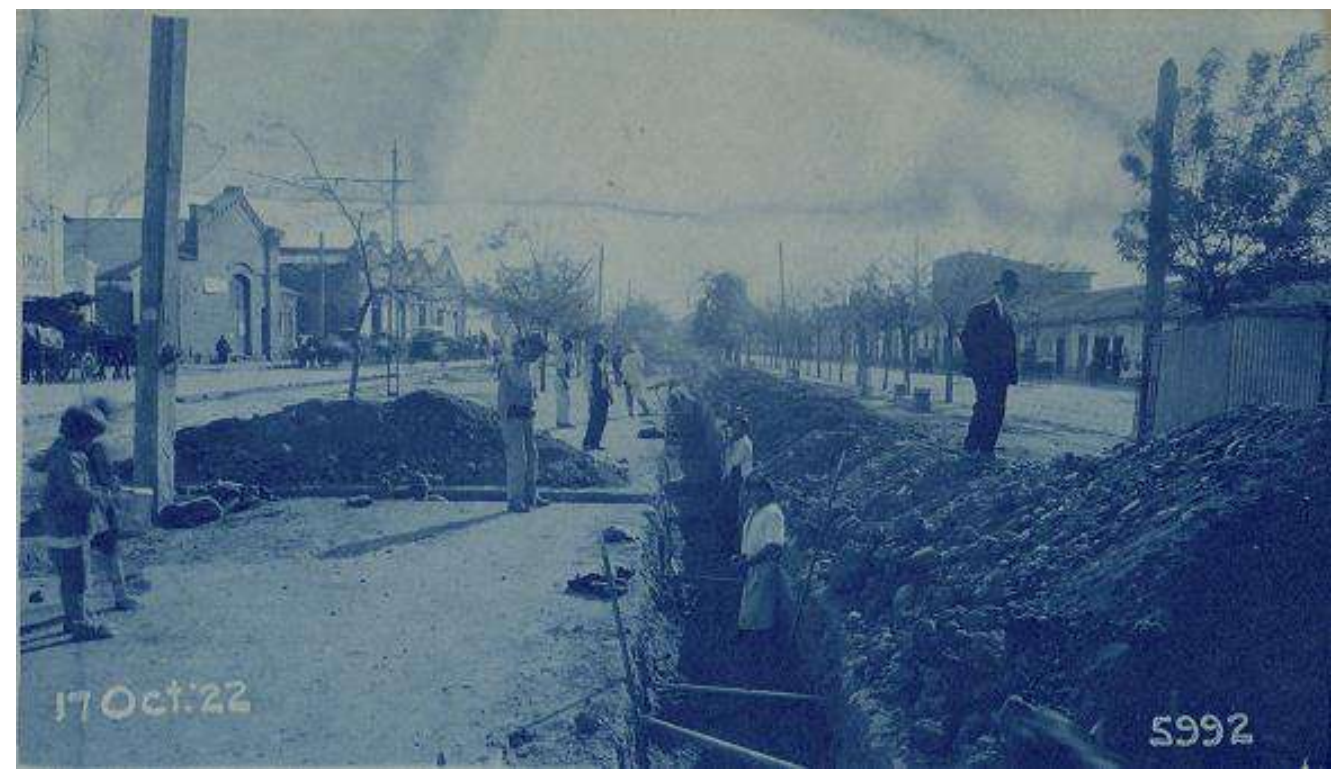

Instalación de la red eléctrica de alumbrado público en Av. Latorre (Alameda) al poniente de la Estación Central, 17 de octubre de 1922. Fuente: Archivo Chilectra, Biblioteca Nacional de Chile.

El avance del ferrocarril en el área tuvo un hito con la creación del ramal hacia Melipilla, en la década de 1890. Este último bordeaba a Chuchunco por el sur, expandiendo la ciudad hacia un sector completamente agrícola y formándose poblaciones de operarios del rubro, como la Santa María (ver figura 4).12 Esto trajo consigo usos industriales que significaron un bajo precio del suelo, estimulando su ocupación por parte de la clase trabajadora, ya que en la Estación Central «siempre se requería mano de obra para diversos servicios». La mayor parte de los residentes optaron por dos modalidades de habitación: el alquiler de piezas en conventillos y el arriendo y compra de sitios para la autoconstrucción. ${ }^{13}$ Debido a que en aquella época no había requisito alguno de las exigencias mínimas que aseguraran la habitabilidad, el descenso de las condiciones ambientales de los pobladores fue evidente, siendo frecuentes los reclamos en torno a la falta de servicios e infraestructura. En gran parte, las denuncias giraban en torno a la carencia de agua potable, pavimentación y regularización de acequias para impedir inundaciones. Esto era expresión del aumento de habitantes: la entonces subdelegación novena rural de Chuchunco duplicó su población entre 1895 y 1907 y totalizó este último año más de seis mil personas (De Ramón, 233-236).

\footnotetext{
${ }^{12} \mathrm{Al}$ oriente de la Estación Central se había desarrollado una expansión urbana siguiendo el eje de calle Exposición, teniendo a las poblaciones de Ugarte y San Eugenio como las más representativas de este proceso.

${ }^{13}$ Consejo Superior de Habitaciones Obreras, Memoria de su labor 19o6-1911 (Santiago de Chile: U. Chile, 1911).
} 
Este proceso trajo consigo además una creciente inseguridad pública. Por ejemplo, en 1895 la Intendencia de Santiago manifestaba que Chuchunco estaba formado por «gente de malas costumbres y bandidos».14 La misma entidad señaló en 1902 que la zona más poblada del barrio estaba «Siempre amagada por los malhechores que llegan por los ferrocarriles y por los que escapan del centro huyendo de la persecución de la policía de la ciudad». ${ }^{15}$ La delincuencia existente también respondía a la presencia de innumerables establecimientos de expendio de bebidas alcohólicas y de diversión popular. ${ }^{16}$ Ya en la década de 1910, la prensa denunciaba que el terminal de Estación Central, se encontraba

... inmediatamente rodeado de callejuelas que son una afrenta para la cultura y la estética de una ciudad como Santiago [...] Basta alejarse del radio de la Estación, para conocer en sus alrededores, pésimas construcciones, falta de alumbrado, un olor que repugna y por lo demás la falta absoluta de moral entre los hombres y mujeres quienes pululan por las calles».17

En suma, este margen de Santiago se expandió sin un plan, con trazados de calles que no consideraron más que los intereses particulares, sumado a la ausencia casi total de servicios y la constante inseguridad pública. Tal como lo mencionamos, este tipo de desarrollo suburbano implicó una baja en el precio del suelo, convirtiendo a Chuchunco en un sector adecuado para el loteamiento de terrenos, que serían ocupados en su mayoría por los migrantes que llegaban a la ciudad a través del tren, consolidándose como el arrabal más cercano a la Alameda y una de las zonas capitalinas más degradadas.

Pese a la dificultad de crear un trazado urbano regular, poco a poco se fue formando una red de calles y avenidas. Por una parte, en sentido oriente poniente, las avenidas Latorre y Chuchunco, se extendían hacia 1930 cerca de doce cuadras hacia el poniente. Por otra, las calles transversales, abiertas por particulares desde fines del siglo XIX, en forma paralela a la línea del ferrocarril. Este proceso se consolidó hacia 1910 con la apertura de General Velásquez, comprendida como la avenida longitudinal primada de

\footnotetext{
14 Intendencia de Santiago, diciembre de 1892, Citado por De Ramon, «Estudio de una periferia urbana» 227.

15 Intendencia de Santiago, enero de 1902. Citado por De Ramon, «Estudio de una periferia urbana» 225.

${ }^{16}$ Este tipo de espacios correspondían a cantinas, prostíbulos y sitios de juego clandestinos. Estos lugares atraían a una gran cantidad de habitantes citadinos y rurales, entre ellos los bandoleros tan temidos. Ver Juan Carlos Luengo, Cuecas, ferrocarril y mentalidades: una exploración para la historia del barrio Estación Central (190o-1940), Tesis de Magíster en Historia, Santiago de Chile: Universidad de Chile, 2004; Tomas Cornejo, Elisabet Prudant y Maximiliano Salinas, Vamos remoliendo mi alma. La vida festiva popular en Santiago. 1870-189o. (Santiago de Chile: LOM, 2007).

17 «Estación Central y sus alrededores. Un barrio que es una vergüenza», Las Últimas Noticias [Santiago de Chile], feb. 3, 1914: s/p.
} 
este nuevo sector y que el crecimiento urbano traspasó desde la década siguiente, hasta la calle General Amengual, transformada en el límite poniente de Santiago (ver figura 4).

Luego se abrieron y extendieron otras vías transversales, muchas provenientes del sector oriente y que cruzaban la línea férrea al sur del terminal. Entre las principales destacaron Cinco de Abril y Arica (continuidad del camino de cintura sur, actual Av. Blanco Encalada). Estos trazados dieron lugar a manzanas rectangulares y alargadas, las que posibilitaron una subdivisión intensiva de los predios, usualmente con tipologías constructivas de un piso, levantadas en base a albañilería de ladrillo de adobe y fachada continua (ver figura 3). En cuanto a instalaciones industriales, al sur de Antofagasta se emplazó el nuevo Gasómetro de la Fábrica de Gas de Santiago (inaugurado en 1927), que se venía construyendo desde inicios de siglo. ${ }^{18}$ Esto confirmó a Chuchunco como un barrio orientado a los usos industriales y ferroviarios.

Figura 3

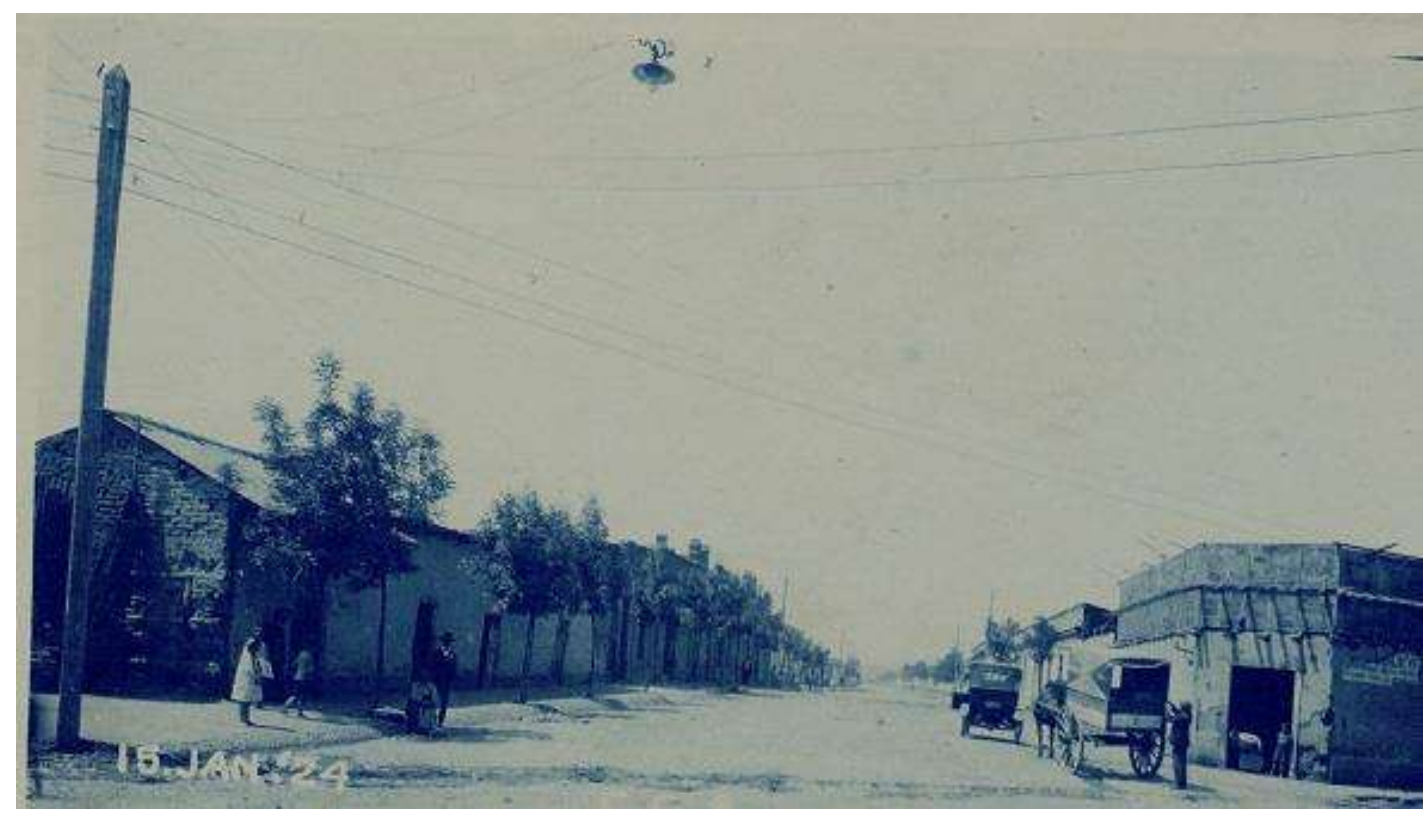

Vista de las calles Jotabeche y Cinco de Abril, 15 de enero de 1924.

Fuente: Archivo Chilectra, Biblioteca Nacional de Chile.

A finales del siglo XIX, la administración del territorio estaba a cargo de la municipalidad de Santiago, constituyendo la subdelegación novena rural, con un bajo número de habitantes. Esto cambió de forma radical a partir del siglo Xx. Según el Censo de Población de 1920, este sector de la ciudad estaba dividido en dos: la comuna de Estación -que era parte de la municipalidad de Santiago- en específico la subdelegación

\footnotetext{
${ }^{18}$ Este establecimiento reemplazó al ubicado más cercano al centro, en el barrio de Yungay, convirtiéndose en un recinto vecino a la línea del ferrocarril a Melipilla. Nazer 140.
} 
Ugarte, en torno al terminal ferroviario. Esta última era un denso arrabal con más de 25 mil personas y formaba el área urbana de Chuchunco. Segundo, estaba la ya señalada subdelegación novena rural Chuchunco, perteneciente a la comuna de Maipú, que totalizaba 6279 habitantes. Debemos tener en cuenta que para entonces otras comunas periféricas de Santiago tenían una cifra considerablemente menor, representando así Chuchunco uno de los mayores aumentos de población en la época. ${ }^{19}$

Hacia finales de la misma década, se produjo un cambio administrativo, el que implicó el traspaso de territorio desde Maipú y Lo Espejo a Santiago. Para entonces, la ciudad contaba con cerca de seiscientos mil habitantes, mientras que los distritos Chuchunco y Gasómetro totalizaban más de diecisiete mil personas, confirmando el alza de población registrada en el censo anterior. En tanto, el área vinculada con la línea ferroviaria hacia el oriente -las ahora llamadas subdelegaciones Exposición y San Alfonso- albergaban veinte mil residentes. ${ }^{20} \mathrm{La}$ acción edilicia de la municipalidad de Santiago se concentró en esta última zona, correspondiente a los barrios más densos, implicando una menor preocupación por el sector ubicado desde Cinco de Abril hacia el sur y de General Velásquez al poniente, es decir, hacia Maipú (ver figura 4). En rigor, este doble trato de la corporación produjo una situación de atraso que afectó a todo el suburbio, en especial al momento de intensificarse los loteos para establecer poblaciones a partir de 1920.

\section{Poblaciones autoconstruidas y servicios en Chuchunco (1920-1933)}

La formación de conjuntos habitacionales en este sector se concretó a través de dos modalidades: la venta y arriendo de sitios a pequeños propietarios y las cooperativas de trabajadores, estas últimas bajo los auspicios de la política de vivienda. En el primer caso encontramos las poblaciones Edwards, General Velásquez, Delicias, Chuchunco, Santa María, Almirante Latorre y Javiera Carrera; respecto al fomento estatal, la más destacada fue la población Juan Bonhomme, del gremio de peluqueros, que abordaremos en la última sección de este artículo.

\footnotetext{
19 Como comparación, hacia 1920 algunos de los municipios suburbanos de Santiago, como Yungay en el poniente, llegaban a los quince mil habitantes, mientras que, al oriente, Nuñoa superaba los dieciséis mil. República de Chile, Dirección General de Estadísticas. 1925. Censo de población de la República de Chile: levantado el 15 de diciembre de 1920, Santiago, Imprenta Universo, pp. 41-44.

${ }^{20}$ República de Chile, Dirección General de Estadística, Resultados del X Censo de la Población efectuado el 27 de noviembre de 1930 y estadísticas comparativas con Censos anteriores (Santiago de Chile: Ed. Universo, 1931): 103.
} 
Figura 4.

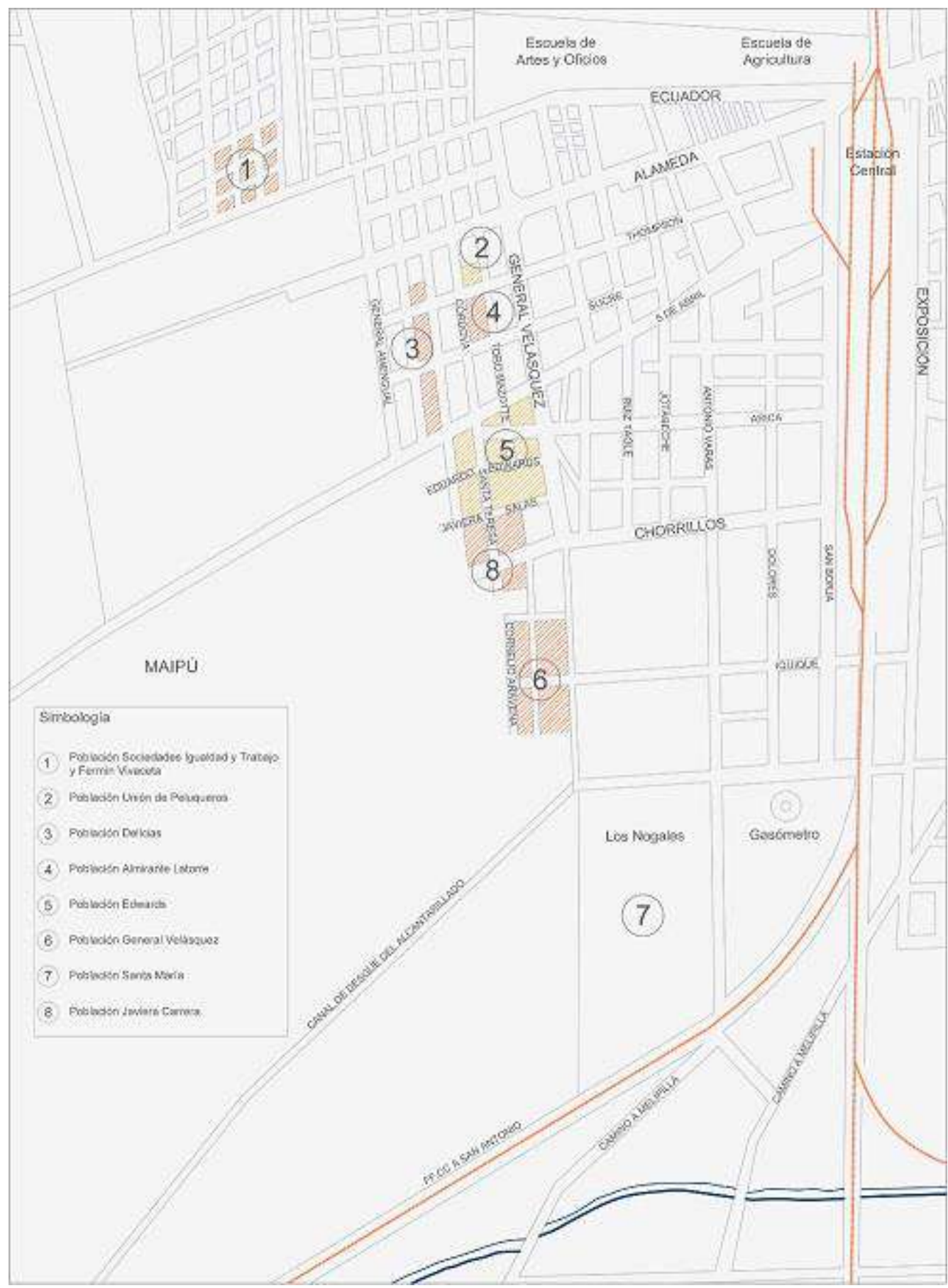

Plano de las principales poblaciones de Chuchunco, 1931.

Fuente: José Peña, Santiago y sus alrededores, Imprenta Universo, 1931 y Boletín Municipal, 17-3-1931: 3-5.

Dentro de las deficiencias de la mayoría de ellas, estuvieron los servicios e infraestructura, destacando la insalubridad de las acequias. En 1929, el doctor Carlos Molina luego de una visita en terreno, indicó que:

En el barrio de Chuchunco, la gran parte de sus habitantes carecen de alcantarillado, y en las que este existe, se encuentran todavía acequias a tajo abierto, sin cegar, cubiertas de cieno y desperdicios; el agua corriente en las acequias no es constante, lo que como es natural produce malos olores, de los cuales se queja todo el vecindario y son en realidad un verdadero foco de 
infección; se me aseguró por personas responsables que las acequias habían permanecido sin agua hasta por cuatro meses, debido a la falta de pago de los propietarios de ellas por sus derechos a los canalistas; la vuelta del agua encontró a las acequias sin limpia [limpieza] alguna, produciéndose tacos que obligaban a efectuar derivaciones de ellas, dejando como es de presumir, lleno de desperdicios el interior de las casas, que no han originado una epidemia por el gran fondo que tienen, lo que deja a las acequias alejadas de las habitaciones. ${ }^{21}$

Estas condiciones eran similares en la población General Velásquez, en el margen sur del barrio (ver figura 4) y que, con más de dos mil habitantes a inicios de los años 1930, era uno de los conjuntos más densos. Sus terrenos fueron subdivididos por el particular Germán Yunge desde 1926, siendo parte entonces de la comuna de Lo Espejo, en el extremo sur poniente de Santiago. ${ }^{22}$ Los sitios fueron ocupados rápidamente a través de una autoconstrucción progresiva, contando con agua potable y alumbrado eléctrico, pero careciendo de pavimentación y alcantarillado. Esto último significó, como indicó el doctor Molina, utilizar las acequias y volverlas insalubres. En este panorama, sus vecinos se organizaron en una Sociedad Pro-Adelanto Local, que en febrero de 1927 solicitaba al dueño del conjunto, mediante la prensa, que se hiciera cargo de la provisión de servicios básicos «y pedirle cumpla con los reglamentos de la población».23 Frente a la nula respuesta de Yungue, los afectados recurrieron a la municipalidad de Santiago, que para entonces tenía bajo su tutela dicha urbanización. En 1930, los abogados de la corporación evacuaron el informe jurídico solicitado por los vecinos e indicaron que era necesario que:

... la Alcaldía de Santiago obligue al propietario, don Germán Yungue, a cumplir con las exigencias que establece el artículo 46 de la Ley de Municipalidades vigente: Los vecinos y propietarios de la susodicha población han denunciado la situación irregular en que ella se encuentra con relación a los preceptos de la ley de municipalidades vigente y piden que esta autoridad local aplique las sanciones del caso, a fin de obtener que don Germán Yungue, propietario y formador de la población, someta a su consideración y aprobación el plano respectivo y la dote de los servicios de desagüe y de pavimentación...24

La solicitud municipal se sustentó en el Decreto Ley (DL) 740 de 1925, cuyo artículo 46 entregó a los municipios la responsabilidad de la recepción de los conjuntos habitacionales formados en su territorio, siempre y cuando estos contaran con servicios. En este caso, se experimentaba una urbanización informal basada en el afán de lucro de los propietarios, sin respetar la legalidad vigente y demostrando, por otra parte, que el municipio tampoco podía proceder hasta que se resolviera el conflicto legal suscitado. En

\footnotetext{
${ }^{21}$ Médico Jefe de Sanidad y de Carabineros a Intendencia. Intendencia de Santiago, may. 31 de mayo de 1929. Archivo Nacional de Chile (ANCH), Santiago, Fondo Intendencia de Santiago, vol. 682.

${ }^{22}$ El territorio en que se encontraba ubicada la Población General Velásquez fue anexado al municipio de Santiago por Decreto Supremo el 31 de diciembre de 1928.

23 «Población general Velásquez», La Nación [Santiago de Chile], feb.15, 1927: 14.

24 «Municipalidad de Lo Espejo a la Municipalidad de Santiago», Boletín Municipal [Santiago de Chile], 13 de jun. 1930: 9 .
} 
general, estas características se repetían en todas las periferias populares del Santiago de la época. Por ello, eran los propios pobladores los encargados de solucionar las dificultades enfrentadas.

Junto con la señalada Sociedad de Adelanto Local, desde la década de 1920, las fuentes informan respecto a las actividades del «Comité de Dueños de Mejoras» del extenso barrio situado al poniente de Estación Central, agrupando a miles de personas que buscaban el reconocimiento económico a las modestas edificaciones levantadas, algunas incluso hacía varias décadas. Esta organización estableció una directa comunicación con pares locales y de otras urbes como Valparaíso y La Calera. Así, el conjunto de las organizaciones capitalinas indicaba en 1928 que «podemos asegurar que todos los arrendatarios de piso ocupamos un tercio del radio urbano de la ciudad de Santiago».25 Para 1932, el grueso de los mejoreros de Chuchunco estaba adherido a una nueva y más amplia entidad, la Asociación Nacional de la Habitación. ${ }^{26}$ Por ello, el problema de la vivienda en aquel barrio expresó con fuerza las dificultades experimentadas -además de los compradores de lotes-por los arrendatarios. Y, por otra parte, esta modalidad de habitar trajo consigo una intensa asociatividad barrial que se articuló a escala nacional.

Esta convergencia de compradores y «mejoreros» se vivía en la población General Velásquez y se repetía en los terrenos que formaban parte de la chacra de la familia Edwards Sutil, «ubicados al Poniente de la Av. General Velásquez y al sur de la calle Cinco de Abril», sitios que también habían sido adquiridos por el mencionado Yungue, pero que no correspondían al núcleo original de la General Velásquez, sino que a otros negocios inmobiliarios. Se creó así la población Edwards (ver figura 4).27 Como indicamos, el territorio que quedaba al poniente de la Av. General Velásquez no tenía mayor atención municipal, conformando uno de los sectores más periféricos de Chuchunco y, por ende, de la ciudad. En ese escenario, no es de extrañar que en 1927 se denunciara que la población Almirante Latorre, emplazada dos cuadras al poniente de la vía mencionada

\footnotetext{
25 Vidal Matte, El problema de los arrendamientos de piso. (Santiago Ed. Talleres del Diario Ilustrado, 1928), 4. Mayores antecedentes respecto a la actividad del Comité de Mejoras de Chuchunco en «Asamblea extraordinaria celebrará el Comité Dueños de Mejoras», La Nación [Santiago de Chile], jun. 30, 1929: 53. «Ayer se iniciaron las labores de la Segunda Semana de la Habitación», El Diario Ilustrado [Santiago de Chile], abr. 20, 1931: s/p.

${ }_{26}$ «Celebraron asamblea pública los pobladores de Chuchunco», Los Tiempos [Santiago de Chile], jul. 28, 1932: 15 .

${ }_{27}$ Jorge Calvo Mackenna a Intendente de Santiago, oct. 11, 1927. ANCH, Santiago, Fondo Intendencia de Santiago, vol. 606.
} 
(ver figura 4) y habitada por «más de 60 familias de obreros que han construido modestas viviendas», se encontrara «sin alumbrado, sin pavimento y sin servicios higiénicos». La situación no solo contravenía la ley, sino que debían enfrentar la delincuencia estimulada por la ausencia de alumbrado público, el pésimo estado de calles y veredas que en invierno se convertían en lodazales y la falta de aseo por parte del municipio. Frente a estas adversidades, los vecinos se organizaron en una de las ya mencionadas Sociedad ProAdelanto Local, efectuando gestiones ante la municipalidad de Santiago e incluso al gobierno central, obteniendo como respuesta que la falta de fondos impedía las obras de infraestructura necesarias. A raíz de su impacto en la reducción de la delincuencia, una de las solicitudes principales era la extensión de la electricidad, indicando que «ahora que se está dotando de nuevo y buen alumbrado público a Santiago y que este llegará hasta [...] cinco cuadras más allá [al poniente] de esta población, bien podría la autoridad atender a esta necesidad vital para el desarrollo de este barrio».28

Figura 5

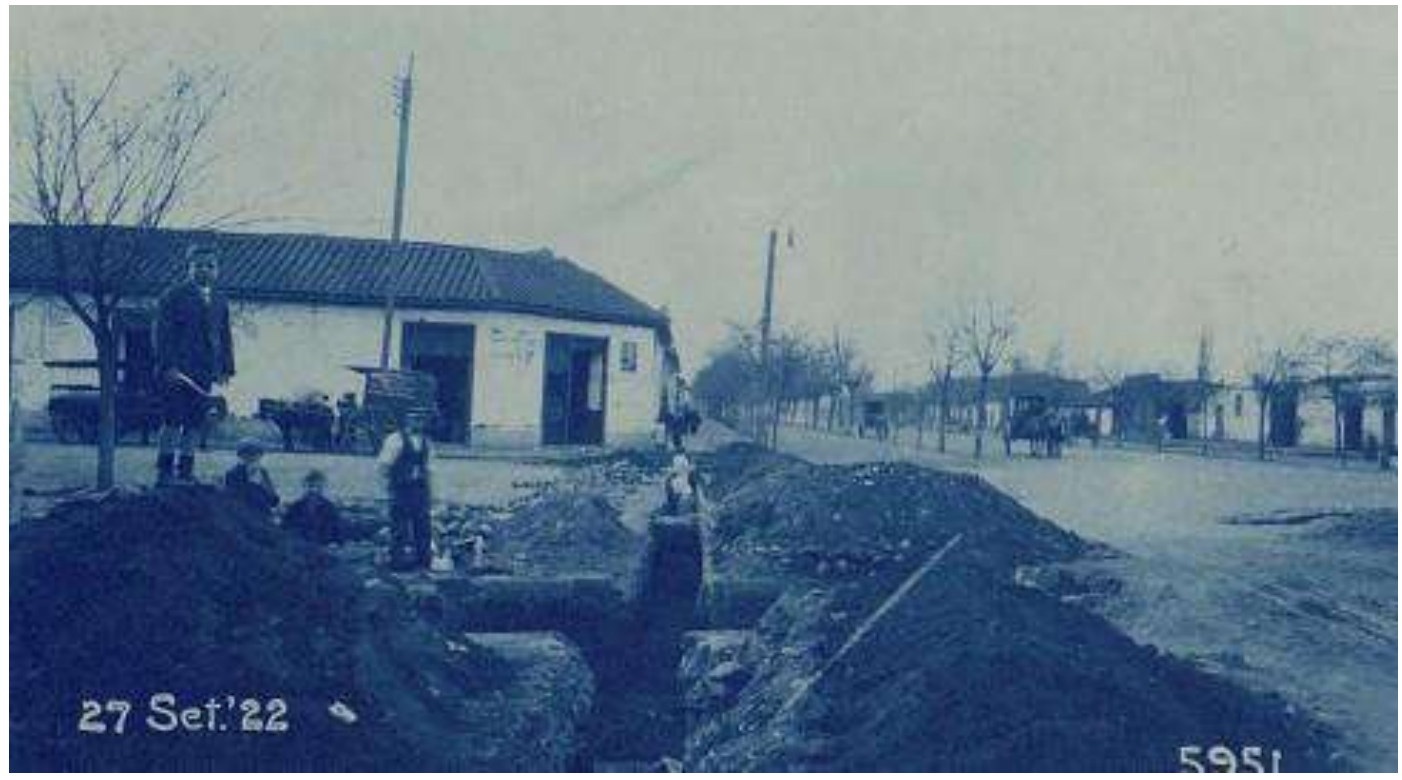

Instalación de la red eléctrica de alumbrado público en el cruce de avenidas Latorre (der.) y General Velásquez, 27 de septiembre de 1922. Fuente: Archivo Chilectra, Biblioteca Nacional de Chile.

La ampliación de la red eléctrica fue también prioritaria para los vecinos de la calle General Amengual, ubicada en el extremo poniente de la ciudad. En 1927, solicitaron dicho servicio

28 «Otra población obrera sin alumbrado, sin pavimento y sin servicios higiénicos», La Nación [Santiago de Chile], jun. 22, 1927: 19. Respecto a la asociación entre la falta de alumbrado público y la delincuencia en Argentina durante el mismo período, Lila Caimari, Mientras la ciudad duerme. Pistoleros, policías y periodistas en Buenos Aires, 1920-1945, Buenos Aires: Siglo Veintiuno Editores, 2012. 
y que continúe la plantación de árboles, a fin de que se cumpla la aspiración de prolongar la Alameda más allá de la Estación Central. Al mismo tiempo se protege de la gente maleante que de día se aprovecha de la obscuridad, con las medidas que se solicitan de la escasa vigilancia para desarrollar su actividad. ${ }^{29}$

El reclamo por la seguridad pública se extendía a la mayoría de los conjuntos. Por lo mismo, en 1928 más de seiscientas familias que vivían a unas diez cuadras hacia el sur de la Alameda, agradecían la reciente instalación de un retén de Carabineros, «orijinada [sic] por los constantes asaltos y otros actos delictuales que en el referido barrio se cometían casi a diario». Frente a la noticia de un posible traslado de esta unidad policial y sin luz artificial en las calles, los pobladores apelaban «la necesidad imperiosa de mantener este Retén en el sitio en el que actualmente se encuentra, ya que, de lo contrario, volverá a sufrir el vecindario los actos delictuales que movieron a ordenar dicha vigilancia, nos encontramos nuevamente amenazados de quedar entregados al más absoluto abandono».30 En general, el alumbrado eléctrico se restringió a las principales vías, como Av. Latorre, General Velásquez y Cinco de Abril (ver figuras 2, 3 y 5). Su operación estaba a cargo de la Compañía Chilena de Electricidad (1921), empresa privada que extendía la red de acuerdo al presupuesto municipal.

Como entidad responsable, la corporación de Santiago se mostró incapaz de asumir el desafío de cubrir con sus servicios a todo Chuchunco. Por ello -y en un contexto político autoritario- hacia fines de la década de 1920, el presidente Carlos Ibáñez autorizó una intervención directa por parte de la Intendencia, indicando en un telegrama al jefe provincial que «Varias veces he conversado con Ud. sobre la necesidad de urbanizar siquiera en parte el barrio de Chuchunco. Nuevamente veo una solicitud en que los pobres vecinos de ese barrio reclaman atención para sus necesidades». ${ }^{31}$ El mandatario enfatizó en la necesidad de esta modernización por varios motivos: el mal estado en general de los caminos periféricos de Santiago, todavía más grave en el caso de Chuchunco, al ser Av. Gener.al Velásquez una de las arterias relevantes del sector (ver figura 5). En este sentido, dicho tipo de transformaciones eran entendidas como una representación de progreso, uno de los pilares de la dictadura ibañista (Valdivia, 2017, 104). Esta apuesta por mejores

\footnotetext{
29 «Por el progreso del barrio Alameda y Av. General Amengual. Una petición de los vecinos a la intendencia municipal», La Nación [Santiago de Chile], jul. 25, 1927: 13.

${ }^{30}$ Solicitan la permanencia de un retén de Carabineros, dic. 8, 1928. ANCH, Santiago, Fondo Intendencia de Santiago, vol. 627 .

${ }^{31}$ Telegrama del presidente Carlos Ibáñez a Intendente de Santiago, feb. 15, 1929. ANCH, Santiago, Fondo Intendencia de Santiago, vol. 664.
} 
vías se insertaba en el programa de gobierno como una manera de promover el transporte motorizado por sobre otras formas de movilidad (Errázuriz, 2010, 357-411).

En ese contexto, fue presentado el proyecto municipal de reforma de la Av. General Velásquez, como parte de una modernización mayor del área. La propuesta contemplaba obras de pavimentación «de adoquín sobre concreto, de primera clase», que se extenderían a las calles San Borja y Cinco de Abril y «la transformación de la Avenida General Velásquez, la que tendrá paseos laterales y una calzada pavimentada al centro, al igual de la Avenida Vicuña Mackenna [...] será dicha vía una parte muy importante de aquella Gran Avenida de Circunvalación que cerrará el verdadero barrio urbano de la ciudad».32 Asimismo, esta iniciativa se hacía cargo del grave problema de conectividad que traía la presencia de la línea del ferrocarril longitudinal al sur, al interrumpir la continuidad de las calles en dirección oriente poniente. Para esto, la misma fuente, indicaba que era necesario iniciar los estudios de pasos bajo nivel «que unan las calles del barrio que nos preocupa con las que son su continuación hacia la ciudad». Por último, se proyectaba incorporar áreas verdes, bajo una idea de hermoseamiento general del barrio, donde la Av. General Velásquez tendría un rol crucial, al instalarse una plaza en su extremo sur. Todos estos trabajos pretendían proporcionar un mayor estándar urbanístico a Chuchunco, intentando igualar algunos aspectos de la ciudad consolidada, como, por ejemplo, elevar la materialidad de la arteria mencionada al rango de Av. Vicuña Mackenna, una de las principales del centro de la capital y que constituía el límite oriente de la Municipalidad de Santiago. En este caso la Av. General Velásquez sería el cierre poniente del «verdadero barrio urbano de la ciudad».33

Con todo, la realidad de los espacios públicos y privados de Chuchunco estuvo marcada por una coexistencia cotidiana con desechos humanos y animales. Aunque la acumulación de basura en boquerones hechos en los patios de las casas era una costumbre extendida en todas las periferias santiaguinas, en este sector su magnitud alcanzaba niveles que sorprendían a los propios contemporáneos. En 1927, los moradores de la población Almirante Latorre ofrecían su propia mano de obra para cambiar el deteriorado entorno, alegando que:

${ }^{2}$ Oficio n. ${ }^{\circ} 74$, del Sr. Alcalde de Santiago referido a la urbanización barrio poniente de la ciudad, mar. 1, 1929. ANCH, Santiago, Fondo Intendencia de Santiago, vol. 692.

33 Oficio n. ${ }^{\circ}$ 74, del Sr. Alcalde de Santiago referido a la urbanización barrio poniente de la ciudad, mar. 1, 1929. ANCH, Santiago, Fondo Intendencia de Santiago, vol. 692. 
... las autoridades, aunque escasas de recursos, pueden no obstante contribuir al mejoramiento de nuestro barrio, haciendo que lleguen hasta aquí algunos carretones de la Policía de Aseo, con ripio para rellenar los hoyos, obsequiándonos algunos árboles para plantear en las calles y en fin, suministrándonos cualesquier [sic] elemento que sirva para mejorar las vías públicas. 34

En cierta medida, el proyecto de reforma de 1929 para Av. General Velásquez trajo consigo durante un tiempo una mayor preocupación por el entorno y la salubridad pública, señalando que la única obra ejecutada hasta entonces era «un aseo extraordinario completo, con una dotación de material de aseo sacado de las diversas reparticiones del servicio de toda la ciudad. Se han extraído de las calles y de las propiedades particulares enormes cantidades de escombros y de basuras, y se ha hecho el aseo y el relleno de varios sitios en donde había aguas pútridas detenidas».35 Un año después, el importante medio de orientación conservadora El Diario Ilustrado publicó una serie de reportajes sobre el estado de la periferia de la ciudad, donde se dejaba en claro que en Chuchunco poco había cambiado. Como evaluación general, el medio tildó al sur poniente capitalino como el suburbio en peores condiciones materiales, destacando la desmejorada vialidad, la falta de alumbrado, la nula existencia de un servicio de aseo y la desorganización general del barrio. Uno de los temas principales en que se reparó fueron las acequias malolientes, extendidas por todos los sectores y sirviendo de basurales. Además, el diario enfatizó en la pobreza de Chuchunco y en particular al poniente de la línea del ferrocarril, señalando de manera tajante que «Eso no es ciudad ni pueblo, sino un enorme chiquero. Chicuelos harapientos, flacuchos y pálidos nos reciben y acompañan por todas partes». 36

La existencia de deshechos de todo tipo y micro-basurales evidenció también la desidia municipal, reforzando la segregación urbana vivida por los moradores de Chuchunco. Por ejemplo, en la población Delicias, un conjunto edificado para obreros ferroviarios y que se emplazaba al poniente de Av. General Velásquez (ver figura 4), los residentes solicitaron en 1930 al alcalde una mayor regularidad en la recolección de desechos, con el fin de obtener un funcionamiento a diario o al menos cada dos días. Sin embargo, el edil de Santiago, Eliecer Parada, respondió que «tomando en cuenta el aumento enorme de nuevas poblaciones en el sector al poniente de la Estación Alameda

\footnotetext{
34 «Otra población obrera sin alumbrado, sin pavimento y sin servicios higiénicos», La Nación [Santiago de Chile], jun. 22, 1927: 19.

35 Oficio n. ${ }^{\circ} 74$, del Sr. Alcalde de Santiago referido a la urbanización barrio poniente de la ciudad, mar. 1, 1929. ANCH, Santiago, Fondo Intendencia de Santiago, vol. 692.

36 «Sin servicios de aseo, en cada casa se mantienen botaderos de basura», El Diario Ilustrado [Santiago de Chile], may. 17, 1930: s/p.
} 
y el mayor porcentaje de basuras en esta época de verano, no es posible hacer el aseo día por medio o diariamente, como sería de desear». 37 Los inconvenientes se agravaban por el paso de la acequia Chuchunco, perteneciente a la Sociedad del Canal del Maipo y que inundaba las casas con frecuencia, como denunciaron los residentes en $1932.3^{8}$ Las críticas al desempeño de la Policía de Aseo se repetían en la zona norte del barrio, en específico, aquellos «que viven en las calles Toro Mazote, hasta la Avenida General Amengual, entre Delicias y Ecuador [que], soportan desde hace más de un año el grave peligro de las numerosas acequias a tajo descubierto que atraviesan estas manzanas. Estas acequias durante un año han permanecido secas, con evidente peligro para la salud de las personas». De este modo, más de cien vecinos denunciaban en 1930 que, pese a los innumerables reclamos al jefe de dicha sección municipal, los resultados habían sido nulos, resaltando que «ya llega la época de calores intensos, propicia para incrementar los focos de infección».39 De esta manera, las grandes limpiezas del barrio acometidas por la municipalidad se remitieron a ciertas coyunturas, sin asentarse como una medida permanente.

En cierta medida, fue el poder Ejecutivo quien proporcionó soluciones más duraderas, aunque estuvo lejos de cubrir la totalidad de Chuchunco. Dentro de los principales proyectos impulsados por la dictadura de Ibáñez y proseguido durante la presidencia de Arturo Alessandri (1932-1938) estuvo, además del mejoramiento y ampliación del sistema vial, optimizar el estado higiénico de la ciudad, en especial la evacuación de las aguas servidas, fortaleciendo la red de alcantarillado.40 Por ello, la administración ibañista apostó a la progresiva masificación de los servicios sanitarios, sobre todo en las comunas suburbanas. ${ }^{41} \mathrm{El}$ mismo presidente señaló en 1930 que «El mejoramiento de los servicios higiénicos en el país ha traído como consecuencia lógica la

\footnotetext{
37 «Extracción de basuras en la población Delicias», Boletín Municipal [Santiago de Chile], 3 mar. 1930: 1353.La población Delicias fue edificada por la Caja de Retiros y de Previsión Social de los Ferrocarriles del Estado. Se emplazó al poniente de Av. General Velásquez y estuvo compuesta por alrededor de cincuenta hogares. Sin embargo, como vimos, pese a ser creada bajo la tutela estatal -mediante el Ministerio de Bienestar Social- presentaba distintas falencias en cuanto a sus servicios.

38 «Prórroga a la Sociedad Canal de Maipo para hacer obras en el canal Chuchunco o dejarlo en condiciones de ser cegado», Boletín Municipal [Santiago de Chile], 23 jul. 1932: 2040.

39 «En deficientes condiciones de higiene está Chuchunco, dicen los vecinos de ese sector en una presentación que hicieron al Alcalde», La Nación [Santiago de Chile], oct. 27, 1930: 10.

$4^{\circ} \mathrm{El}$ alcantarillado se había inaugurado en 1910, para un radio acotado del centro de la ciudad.

${ }^{41}$ «Se declaran obligatorias las uniones domiciliarias de alcantarillado», La Nación [Santiago de Chile], jun. 11, 1929: 13 .
} 
disminución de la mortalidad».42 $\mathrm{Al}$ año siguiente, poco antes de ser destituido, resaltó que «Se han construido canalizaciones de alcantarillados al Nor-Oriente y al Sur-Poniente de la ciudad, las que han permitido dotar de este servicio a barrios densamente poblados, cuyo estado higiénico dejaba mucho que desear».43 Se observa así en el caso de Chuchunco una especial atención por parte del mandatario, que, junto a las obras de mejoramiento de Av. General Velásquez - muchas de ellas no realizadas- procuró una exhaustiva higienización del barrio.

Las canalizaciones comenzaron en 1928, a través de conexiones domiciliarias al alcantarillado. Se decretó entonces «el saneamiento de 1.259 propiedades», comprendiendo el sector ubicado al poniente de la Estación Central hasta Av. General Velásquez y por el sur hasta la calle Antofagasta, esto es, gran parte del territorio de nuestro análisis (ver figura 4).44 El mismo año, la Dirección del Alcantarillado y Pavimentación de Santiago, perteneciente al Ministerio de Bienestar Social, dio a conocer que dentro de sus estudios de obras nuevas estaba el área excluida por los anteriores trabajos, en particular la población Javiera Carrera (ver figura 4) y el barrio circundante, es decir, al sur de Cinco de Abril, intentando cubrir con esta modernización al poniente de Av. General Velásquez y que como vimos, carecía por completo de este servicio.45 A finales de 1931, los trabajos estaban finalizados, incorporando a buena parte de Chuchunco a la red sanitaria. ${ }^{46}$ Con ello, este suburbio capitalino fue uno de los primeros de la ciudad en contar con esta infraestructura, la que se extendió lentamente por el barrio durante aquella década.

\footnotetext{
$4^{2}$ República de Chile, «Mensaje con que el presidente de la República da cuenta al Congreso Nacional del estado administrativo y político de la nación el 21 de mayo de 1930»(Santiago de Chile: Imprenta Nacional, 1930): 60.

43 República de Chile, «Mensaje con que el presidente de la República da cuenta al Congreso Nacional del estado administrativo y político de la nación el 21 de mayo de 1931» (Santiago de Chile: Imprenta Diario Oficial, 1931): 9.

44 República de Chile, Memoria del Ministerio de Bienestar Social correspondiente al año 1928, Santiago de Chile: Dirección General de Talleres Fiscales de Prisiones, 1929): 643-644. Este mismo decreto declaró afecto a otra periferia de la ciudad, como era la norte en el sector de plaza Chacabuco.

45 República de Chile, Memoria del Ministerio de Bienestar Social correspondiente al año 1928, Santiago de Chile: Dirección General de Talleres Fiscales de Prisiones, 1929): 636-638. Esta Dirección había sido creada en el contexto de reformas sociales de 1925 a través del DL 567, de 29 de septiembre de aquel año, formando parte en ese entonces de la Intendencia de Santiago. «El mejoramiento higiénico del país. Servicios de alcantarillados y agua potable», La Nación [Santiago de Chile], jun 25, 1929: 4. La población Javiera Carrera fue un conjunto levantado por el Estado e inaugurado en 1931, compuesto por 318 unidades con más de mil quinientos residentes. Montserrat Palmer, Patricio Gross y Óscar Ortega, «La vivienda social chilena 1900/50", en Documento. Reseña de la vivienda social en Chile, separata revista CA (1988), p. 34 .

46 «Servicio de alcantarillado en diversos barrios de la ciudad», Boletín Municipal [Santiago de Chile], 9 ene. 1932: 1878.
} 
Sin duda que los avances en vialidad y canalizaciones fueron importantes, pero no incluyeron a amplias zonas de la periferia sur poniente de Santiago, las que mantuvieron su estado de deterioro y atraso. Para la prensa, Chuchunco seguía siendo habitado por «una numerosa población compuesta en su mayoría de familias pobres y que viven misérrimamente y que no conocen todavía las ventajas del progreso urbano. Parecen aisladas de la capital».47 Esa condición ambivalente entre lo rural y lo urbano se profundizaría en los años siguientes, a causa del surgimiento de la continuación de este patrón de urbanización informal que involucraba un creciente número de personas pertenecientes a las clases bajas. 48 En 1933, el «Comité Pro-Adelanto Local de Chuchunco» instaba al municipio a dotar de agua potable a vastos sectores del vecindario que aún no contaban con el vital servicio.49 Con todo, esta cruda realidad tuvo un contrapunto que, pese a su limitado tamaño y beneficiarios, pasó a albergar hogares higiénicos para obreros, construidos bajo los auspicios de la política estatal.

\section{La población de la Unión de Peluqueros, un caso de política habitacional en Chuchunco (1925-1931)}

Tal como vimos, hacia 1920, el problema de la vivienda representaba una transición de los modos de habitar de la sociedad popular santiaguina. Por una parte, se encontraba el conventillo y por otra -aunque menos masivo- las poblaciones por venta y arriendo de sitios sin urbanización. El primero ocurría prácticamente en toda la urbe; el segundo, se estaba convirtiendo en una forma frecuente de acceder a la casa propia a través de la autoconstrucción en los márgenes. Como parte de las leyes sociales de $1925 \mathrm{y}$ para frenar este último fenómeno, fue dictado el ya mencionado DL 740, para regularizar los loteos, siendo acompañado del DL 308, destinado al levantamiento de casas «sanas, seguras y de bajo precio», orientadas en especial a segmentos con capacidad de ahorro.50 La ley promovió la ejecución de proyectos de manera directa por el Estado e indirecta por medio de las cooperativas de vivienda. En este último grupo se insertó la población de la

\footnotetext{
47 «Sin servicios de aseo, en cada casa se mantienen botaderos de basura», El Diario Ilustrado [Santiago de Chile], may. 17, 1930: s/p.

48 En 1933, una encuesta sobre la infancia en situación de indigencia constató que el problema era especialmente grave en Chuchunco, por ejemplo, «el $10 \%$ de las familias no tiene cama en que dormir, el $90 \%$ recibe ayuda de alimentación fiscal o particular. El $64 \%$ de los niños en edad escolar no asiste a clase». «Un informe desconsolador», Acción Social [Santiago de Chile], jun. 1933: 17.

49 «Sobre solicitud de los vecinos de Chuchunco», Boletín Municipal [Santiago de Chile], 13 abr. 1933: 2259. $5^{0}$ República de Chile, Memoria del Ministerio de Bienestar Social correspondiente al año 1928, Santiago de Chile: Dirección General de Talleres Fiscales de Prisiones, 1929): 9.
} 
Unión de Peluqueros, también conocida como Juan Bonhomme, en honor al que los trabajadores consideraban como «nuestro patrono y gran obrero».51

El DL 308 proporcionó exenciones tributarias a las cooperativas para fomentar la construcción, implicando un importante aumento en el número de casas que, sin embargo, debido al creciente déficit, fue insuficiente para resolver el problema en el país. Con todo, diversos conjuntos - sobre todo para empleados públicos y miembros de las Fuerzas Armadas y Carabineros - fueron edificados por gran parte del radio capitalino.52 La población Juan Bonhomme es representativa de ese tipo de acción colectiva y un ejemplo de cómo las autoridades veían en ese tipo de emprendimientos una manifestación del patriotismo, la salubridad y moral pública y la organización de la clase obrera dentro de los marcos legales.

Poco después de publicado este decreto, la Unión de Peluqueros convocó a una junta general para conocer el interés de sus socios en acogerse a la ley.53 Como resultado, el gremio levantó entre 1927 y 1931 y en forma paralela, dos conjuntos habitacionales. El primero estaba ubicado en la zona sur de Santiago, inaugurado en 1928 y compuesto por cuarenta casas «cómodas e higiénicas» en «estilo chalet».54 $\mathrm{El}$ segundo proyecto fue la población Juan Bonhomme, situado a menos de una cuadra de la Alameda, entre calles Toro Mazotte y Córdova, con cuarenta y seis unidades en lotes de 8 por 16 metros, edificados en fachada continua (ver figura 4). La modalidad más frecuente tenía tres habitaciones más cocina y baño, junto a un pequeño patio al fondo de la propiedad, al que se accedía a través de un largo pasillo, contando con alcantarillado y la pavimentación de sus calles.55 Así, las casas de este conjunto imitaban la tipología más frecuente en Chuchunco y en el resto de la ciudad, esto es, la fachada continua.

La institución encargada de llevar adelante estas poblaciones y recibir las solicitudes e inquietudes de los trabajadores fue el Departamento Técnico de la

\footnotetext{
51 «Con todo éxito se inauguró ayer la población obrera "Juan Bonhomme”», La Nación [Santiago de Chile], abr. 27, 1931: 19 .

$5^{2}$ Este marco legal se mantuvo hasta fines de la dictadura de Carlos Ibáñez (1927-1931), cuando fue promulgada la Ley n. ${ }^{\circ}$ 4.391, de Fomento de la Habitación Barata (12 de marzo de 1931).

53 «La Unión de Peluqueros ante el problema de la habitación», La Nación [Santiago de Chile], jun. 3, 1925: 16.

54 «La Población del Gremio de Peluqueros», La Nación [Santiago de Chile], mar. 3, 1928: 16.

55 Sebastián Aguilar, «La vivienda social de Estación Central en dos casos de estudio». Patrimoniourbano.cl. https://patrimonio-urbano.cl/2016/11/17/la-vivienda-social-de-estacion-centralen-dos-casos-de-estudio/, Revisado el 9 de setiembre de 2020.
} 
Habitación, perteneciente al Ministerio de Bienestar Social. ${ }^{56}$ Esta unidad asesoraba mediante su sección de «Cooperativas» a decenas de sociedades de este tipo en la construcción de sus viviendas, dentro de las cuales estaba la de peluqueros. Sus principales ocupaciones fueron hacer un seguimiento financiero, así como proporcionar la capacitación necesaria durante todo el proceso. Este acompañamiento se centraba en la asistencia de un delegado fiscal a las juntas generales de las cooperativas y en la elaboración de «una serie de formularios que sirven [...] a los Cooperados para que ellos sin el auxilio de abogados hagan todas sus tramitaciones, ahorrando en consecuencia buenas sumas de dinero».57 Esta asesoría, sobre todo en materia de recursos, se explicaba por los reiterados casos de estafa y apropiaciones ilícitas. 58

La entidad fiscal acompañó también durante este periodo la urbanización de otras poblaciones de Chuchunco, como la de las Sociedades Igualdad y Trabajo y Fermín Vivaceta (en Delicias esquina General Amengual), cuyas 106 unidades constituían uno de los más numerosos conjuntos del área (ver figura 4).59 Además, esta institución fiscal tuvo un rol mediador en los conflictos producidos por desalojos de mejoreros, aduciendo razones de «justicia social».60 A esta densificación con casas higiénicas se sumó la labor desarrollada por la Dirección de Alcantarillado y Pavimentación, que veló por la correcta conexión domiciliaria a este servicio y el asfaltado de las calles, además de tener una estrecha comunicación con el Departamento Técnico de la Habitación.

Esa modernización técnica fue de la mano con un estímulo a aquellos grupos de la clase trabajadora que adhirieron a los postulados de la dictadura de Carlos Ibáñez. En este escenario, la Unión de Peluqueros fue un gremio característico de las nacientes clases medias que habían desarrollado un proyecto económico en relación con algunos servicios comerciales. Este grupo de trabajadores independientes había logrado un importante grado de consolidación, contando con un local propio, ubicado en la céntrica calle

\footnotetext{
$5^{6}$ «Sobre la situación producida en su población conferenciará hoy el directorio de la Unión de Peluqueros con el ministerio de previsión», La Nación [Santiago de Chile], jul. 19, 1927: 18.

57 República de Chile, Memoria del Ministerio de Bienestar Social correspondiente al año 1928 (Santiago de Chile: Dirección General de Talleres Fiscales de Prisiones, 1929): 207.

58 «Crónica Nacional. Santiago», Revista de la Habitación (segunda edición), [Santiago de Chile], jun. y jul. 1927: 98.

59 República de Chile, Memoria del Ministerio de Bienestar Social correspondiente al año 1928 (Santiago de Chile: Dirección General de Talleres Fiscales de Prisiones, 1929): 179.

60 «Sobre demoliciones de edificios ruinosos», Boletín Municipal, [Santiago de Chile], 26 feb. 1930: 4. En este caso, se trataba de una disputa de competencias con la municipalidad de Santiago que buscaba desalojar a numerosas familias de terrenos pertenecientes a Dolores Echeverría, ubicados en calle 5 de abril, una de las principales de Chuchunco.
} 
Tarapacá, además de poseer una cooperativa de vivienda con una intensa labor. Fueron entusiastas adherentes al gobierno de turno y sus promesas de una reforma social al amparo de los valores nacionales. Estas tuvieron su manifestación más evidente en la estrecha comunicación que logró establecer la institución con el primer mandatario, siempre apelando a un actuar dentro de los marcos legales vigentes. ${ }^{61}$

Uno de los eventos más trascendentes para el gremio durante el período estudiado fue la entrega de su conjunto habitacional en Chuchunco, cuyas cuarenta y seis viviendas beneficiaban a cerca de doscientas personas. En dicha oportunidad concurrieron las más altas autoridades, encabezadas por el presidente de la República y el ministro de Bienestar Social, Dr. Ricardo Puelma. La asistencia del mandatario se justificaba debido a la especial atención que en su agenda ocupó la modernización de este extenso suburbio, a lo que se sumaba constituir un ejemplo destacado de las pretensiones de edificar casas higiénicas, económicas y sólidas. Como ocurría de manera frecuente en este tipo de actos -cubierto profusamente por el diario estatal La Nación- los invitados fueron recibidos por una banda militar y por los dirigentes locales. El encuentro comenzó con la visita de Carlos Ibáñez a cuatro residencias, incluyendo «todo el interior», las que merecieron su reconocimiento por «las inmejorables condiciones de mantenimiento, higiene, ornato, etc. [...] ya que esta población es un modelo en su género y, por consiguiente, propende al mejoramiento progresivo de la habitación sana y barata entre nuestros obreros». ${ }^{62} \mathrm{La}$ actividad central fue la invitación a tomar «once» (merienda típica de Chile consumida a media tarde y que habitualmente consiste en té y pan). La comida sirvió para reunir a las autoridades con los pobladores, siendo el momento de los discursos y agradecimientos. Las mesas, instaladas en una de las calles del conjunto y engalanadas para la ocasión, fueron el escenario perfecto para que el Gerente de la Cooperativa, Víctor Astudillo, explicara las emociones que en ese instante vivían los beneficiarios:

\footnotetext{
Comprenderéis, señores, sin gran esfuerzo, la solemnidad de este momento para las cuarenta y seis familias que, reunidas aquí en este humilde rincón de la enorme y progresista ciudad que ya es la capital de la República, y que después de acariciar como un bello sueño el tener su hogar propio, honrado y tranquilo, coronan al fin sus desvelos y acariciados por los pliegues de cuarenta y seis banderas, son dignas autoridades, el mismo número de células
}

\footnotetext{
61 «Del descanso dominical se ocuparán los peluqueros en la asamblea de hoy», La Nación [Santiago de Chile], jun. 6, 1929: 13. "Unión de Peluqueros felicita al Congreso Obrero por su enérgica actitud en resguardo de la disciplina», La Nación [Santiago de Chile], jun. 8, 1929: 19. «Festival a beneficio de los panificadores organizados efectuado en la Unión de Peluqueros», La Nación [Santiago de Chile], jun. 13, 1929: 25. El gremio de peluqueros, junto a otros grupos de trabajadores, como sindicatos y agrupaciones, fueron parte del movimiento obrero que apoyó la dictadura de Carlos Ibáñez. Rojas, 23.

62 «Con todo éxito se inauguró ayer la población obrera "Juan Bonhomme" », La Nación [Santiago de Chile], abr. 27, 1931: 19 .
} 
sociales que conquistáis definitivamente para el progreso, para el orden y para el porvenir de la República. Este acto que tiene toda nuestra humildad material y toda la grandiosidad que son capaces de sentir nuestros corazones, constituye el bautismo oficial de los hogares en que desde hoy en adelante vivirán nuestros hijos, descansaremos nosotros de nuestras diarias faenas y tejerán nuestras esposas sus desvelos y sus afanes de leales y buenas compañeras. ${ }^{63}$

Así se observa cómo el gremio se posicionaba así desde una identidad de clase trabajadora, que asumía un trato paternalista por parte del Estado y en especial de la figura de Carlos Ibáñez, manifestado en la gratitud al gobierno, así como a los valores del orden, la honradez y el progreso.64 Para los residentes era crucial formar y proyectar una familia en condiciones antes inexistentes, asumiendo que el hombre encontraría en el hogar un lugar de descanso para sus largas jornadas laborales y su mujer, un espacio apropiado para criar a los hijos. Esta valoración se repetía en la mayoría de las poblaciones levantadas bajo el auspicio estatal, sobre todo considerando su diametral diferencia respecto a otras modalidades de habitación popular.

En cuanto a la dimensión urbana, los peluqueros reconocían que el lugar se encontraba apartado de la ciudad consolidada, pero que, pese a ello, constituía un ejemplo a seguir para la expansión de la vivienda obrera en la periferia. Con todo, hay que destacar cómo estos sentidos agradecimientos de los dirigentes no se condecían con lo experimentado a pocas cuadras del conjunto inaugurado. Probablemente, esta opinión de la Unión de Peluqueros se debía a que habían sido escogidos como una de las pocas cooperativas del sur poniente de Santiago beneficiadas. Así, llamaban a impulsar la reforma social mediante el fortalecimiento del rol estatal en el problema habitacional:

\footnotetext{
De todas las leyes sociales es acaso esta que nos permite tener hogar propio, la que el Gobierno debe cuidar con más celo y atención. Los funcionarios encargados de hacerla cumplir deben identificarse con ella, y los obreros que reciben sus beneficios, deben consecuencialmente responder con su honradez y con el cumplimiento de los deberes que ella les señala. ${ }^{65}$
}

Esta adhesión se expresó también en la mención por parte de Astudillo al ex jefe del Departamento Técnico de la Habitación, Manuel Vásquez, quien estuvo a cargo del proceso que llevó a efecto la construcción del conjunto. Según el dirigente gremial, desde «la espontaneidad de nuestros corazones proletarios, quiero dejar en este momento el testimonio de nuestra gratitud colectiva» hacia el exfuncionario, con cuyo nombre incluso se bautizó una de las calles de la población. ${ }^{66}$ Una vez terminado el discurso del dirigente,

\footnotetext{
${ }^{63}$ La Nación [Santiago de Chile], abr. 27, 1931: 19

64 Mayores antecedentes sobre este tema en Espinoza 136-137.

${ }^{65}$ La Nación [Santiago de Chile], abr. 27, 1931: 19.

${ }^{66}$ La Nación [Santiago de Chile], abr. 27, 1931: 19.
} 
tomaron la palabra otros actores involucrados, entre ellos el abogado de la población, García Burr; Alfredo Cruz Pedregal, arquitecto de esta y el Intendente de Santiago. ${ }^{67}$ Acercándose la noche se retiraron las autoridades, satisfechas por el acto presenciado. La inauguración había ensalzado los valores sostenidos por el régimen, mientras que los pobladores pudieron ocupar sus casas de manera definitiva. La política habitacional, por su parte, había instalado un pequeño núcleo en una de las periferias capitalinas más densas, buscando con ello que su condición de población modelo irradiara sus virtudes al vecindario.

\section{Consideraciones finales}

A medida que las poblaciones por venta y arriendo de sitios se posicionaron como alternativa al insalubre conventillo, Santiago fue expandiéndose sin control hacia todas sus periferias, originando suburbios en su mayoría carentes de servicios e infraestructura, siendo la única motivación de sus propietarios obtener el mayor lucro posible. Este fenómeno formó parte de una transición en los modos de habitar de la sociedad santiaguina: aunque el conventillo continuó siendo la alternativa residencial más común, a partir de 1920, comenzó a masificarse el problema de los mejoreros y compradores de sitios a plazo, que experimentaron una constante inseguridad, tanto en términos de escritura de la propiedad como las falencias de la urbanización. Este fue el caso de Chuchunco, donde las poblaciones loteadas al poniente de la línea férrea en general transgredieron la ley, resaltando la falta de desagües, la irregular recolección de basura y la ausencia de alumbrado público con el consiguiente aumento de la delincuencia, entre otras falencias. Como se pudo observar, fueron varios los conjuntos revisados donde los propios residentes debieron gestionar la solución a deficiencias en la urbanización a través de Sociedades Pro-Adelanto Local.

Durante la dictadura de Carlos Ibáñez se produjo la aplicación de las leyes sociales aprobadas poco antes, lo que significó una nueva arquitectura institucional, donde el Ministerio de Bienestar Social fue el principal encargado de la higiene pública y la aplicación de una política de vivienda más ambiciosa. Esta renovada gobernanza para la ciudad se expresó mediante las labores realizadas por el Departamento Técnico de la Habitación y la Dirección General de Pavimentación y Alcantarillado. Estas medidas

\footnotetext{
67 «Ayer se inauguró la Población Juan Bonhomme», El Diario Ilustrado [Santiago de Chile], abr. 27, 1931: 18. El arquitecto Cruz tenía una larga experiencia por proyectos en distintos lugares de Santiago, por lo que constituía un profesional de alto nivel para el desarrollo de esta obra.
} 
fueron prioritarias para el mandatario --en especial en Chuchunco- buscando dignificar la habitabilidad de los sectores trabajadores. Se intentó llegar con reformas urbanas al poniente de la Av. General Velásquez, que, junto con ser el principal eje del sector, constituía una auténtica barrera que marcaba el inicio de los suburbios más alejados: allí donde la ciudad se confundía con el campo.

Esta dimensión política de la reforma urbana consistiría básicamente en un activo rol de las unidades estatales de pavimentación y viviendas, que apoyaron la construcción de varias poblaciones a través de cooperativas obreras. Una de ellas fue el conjunto de la Unión de Peluqueros, representativo de aquellos sectores que adhirieron a la administración ibañista y sus promesas de reforma social y cuya población modelo -pese a su pequeño tamaño- constituyó un hito en el área. Otro actor institucional relevante fue la municipalidad de Santiago, que tuvo numerosas críticas por su desempeño en la provisión de todo tipo de servicios. Esto se debió a la incapacidad de cubrir un territorio tan amplio y a la vez, por priorizar sus recursos en barrios consolidados del casco histórico, evidenciando desinterés en inyectar recursos en este suburbio y reforzando con ello las precariedades originadas por los loteos de particulares. En consecuencia, todos estos proyectos e intervenciones buscaron de manera infructuosa incorporar a Chuchunco a estándares propios de la ciudad consolidada, cuestión que solo se logró en algunos puntos, ya que en gran parte del extenso barrio - cuya densificación continuólas condiciones distaban de poseer las características de una vida urbana moderna.

En suma, este artículo revisó el espacio más densamente poblado del área y busca ser un estudio introductorio para un problema mucho más amplio. En la actualidad, Chuchunco pertenece a la comuna de Estación Central y las contradicciones surgidas debido a la interacción entre agentes inmobiliarios, compradores y arrendatarios en un contexto de escasa regulación ha llevado a un considerable aumento de población y densificación, repitiendo -a otra escala física y demográfica- los procesos vividos a inicios del siglo veinte.

\section{Fuentes citadas}

\subsection{Archivos}

6.1.1. Archivo Nacional de Chile. Fondo Intendencia de Santiago: volúmenes 403, 1914; Vol. 606, 1927; Vol. 682,1929; Vol. 627, 1928; Vol. 692,1929.

\subsubsection{Periódicos}

La Nación, Santiago 
Las Últimas Noticias, Santiago

Los Tiempos, Santiago.

El Diario Ilustrado, Santiago

Boletín Municipal, Santiago

Acción Social, Santiago

Revista de la Habitación (segunda edición), Santiago

\subsubsection{Censos}

República de Chile, Dirección General de Estadísticas. Censo de población de la República de Chile: levantado el 15 de diciembre de 1920, Santiago, Imprenta Universo, 1925.

República de Chile, Dirección General de Estadística. Resultados del X Censo de la Población efectuado el 27 de noviembre de 1930 y estadísticas comparativas con Censos anteriores, Santiago, Impr. Universo, 1931.

\subsubsection{Mensajes Presidenciales a la Nación}

Mensaje con que el Presidente de la República da cuenta al Congreso Nacional del estado administrativo y político de la Nación el 21 de mayo de 1930, Santiago, Imprenta Nacional, 1930.

Mensaje con que el Presidente de la República da cuenta al Congreso Nacional del estado administrativo y político de la Nación el 21 de mayo de 1931, Santiago, Imprenta «Diario Oficial», 1931.

\subsubsection{Otros}

Consejo Superior de Habitaciones Obreras, Memoria de su labor 1906-1911, Santiago de Chile: Impr. Chile, 1911.

Vidal Matte, El problema de los arrendamientos de piso, Santiago de Chile: Talleres del Diario Ilustrado, 1928.

Memoria del Ministerio de Bienestar Social correspondiente al año 1928. 1929. Santiago de Chile: Dirección General de Talleres Fiscales de Prisiones.

\subsection{Bibliografía}

Aguilar, Sebastián, La vivienda social de Estación Central en dos casos de estudio, en https://patrimonio-urbano.cl/2016/11/17/la-vivienda-social-de-estacion-centralen-dos-casos-de-estudio/, revisado el 9 de septiembre de 2020.

Almandoz, Arturo, Modernización urbana en América Latina. De las grandes aldeas a las metrópolis masificadas. Santiago de Chile: Colección Estudios Urbanos Universidad Católica, 2013.

Armus, Diego and Suriano, Juan «The Housing Issue in the Historiography of Turn-ofthe-Century Buenos Aires», Journal of Urban History 24:3(1998): 416-428.

Ballent, Anahí y Liernur, Jorge Francisco La casa y la multitud. Vivienda, política y cultura en la Argentina moderna. Buenos Aires: Fondo de Cultura Económica, 2014.

Cáceres, Gonzalo, «Modernización autoritaria y renovación del espacio urbano: Santiago de Chile, 1927-1931», EURE 62(1995): 99-108. 
Caimari, Lila, Mientras la ciudad duerme. Pistoleros, policías y periodistas en Buenos Aires, 1920-1945. Buenos Aires: Siglo Veintiuno Editores, 2012.

Cornejo, Tomas; Prudant Elisabet; Salinas, Maximiliano, Vamos remoliendo mi alma. La vida festiva popular en Santiago. 1870-189o. Santiago de Chile: LOM, 2007.

Edwards Bello, Joaquín. El Roto. Santiago: Editorial Universitaria, 1983 (quinta edición).

Errázuriz, Tomás, «El Asalto de los motorizados. El transporte moderno y la crisis del tránsito público en Santiago, 1900-1927», Historia 43(2010): 357-411.

Espinoza, Vicente, Para una historia de los pobres de la ciudad. Santiago de Chile: Sur, 1987.

Fauré, Daniel \& Moyano, Cristina (editores), Memoria social de la población Los Nogales (1947-2015). Santiago de Chile: Usach, 2016.

Fauré, Daniel (editor), Memoria social de la población Santiago (1966-2017). Santiago de Chile: Usach, 2018.

Henríquez, Rodrigo, En «Estado Sólido»: políticas y politización en la construcción estatal. Chile: 1920-1950. Santiago de Chile: Ediciones Universidad Católica, 2014.

Hidalgo, Rodrigo, La vivienda social en Chile y la construcción del espacio urbano en el Santiago del siglo $X X$. Santiago de Chile: Pontificia Universidad Católica de Chile, Instituto de Geografía / Ediciones de la Dirección de Bibliotecas, Archivos y Museos, Centro de Investigaciones Diego Barros Arana, colección Sociedad y Cultura, 2004.

Jürgensen, Francisca, De capital poscolonial a capital republicana: transformaciones en la arquitectura cívica de Santiago durante el proceso de consolidación de la República, 1840-1879, Tesis Doctorado en Arquitectura y Estudios Urbanos, Santiago de Chile: Pontificia Universidad Católica de Chile, 2012.

Luengo, Juan Carlos, Cuecas, ferrocarril y mentalidades: una exploración para la historia del barrio Estación Central (1900-1940), Tesis Magíster en Historia, Santiago de Chile: Universidad de Chile, 2004.

Martínez-Delgado, Gerardo, «Derribar los muros. De la historia urbana a los estudios urbanos con perspectiva histórica: propuestas teóricas y metodológicas desde un diálogo interdisciplina». EURE.137 (2020): 5-26.

Morales Herrera, Luis, Voces de Chuchunco. Santiago de Chile: Centro Esperanza, 1989.

Nazer Ahumada, Ricardo, Gasco: historia de la Compañía de Consumidores de Gas de Santiago, 1856-1996. Santiago de Chile: Ediciones Universidad Católica de Chile, 1996.

Palmer, Montserrat, Gross Patricio y Ortega, Óscar «La vivienda social chilena 1900/50», Documento. Reseña de la vivienda social en Chile, separata revista $C A(1988)$.

Pereira Da Silva, María Lais. Favelas cariocas: 1930-1964. Río de Janeiro: Contraponto, 2005 .

Pinto, Julio. «iLa cuestión social debe terminar! La dictadura de Carlos Ibáñez en clave populista, 1927-1931», Historia.53 (2021): 591-630.

de Ramón, Armando, «Estudio de una periferia urbana. Santiago de Chile 1850-1900», Historia.20 (1985): 199-294. 
- Santiago de Chile. (1541-1991). Historia de una Sociedad Urbana. Santiago de Chile: Sudamericana, 2000.

Rojas, Jorge, La dictadura de Ibáñez y los sindicatos (1927-1931). Santiago: Dirección de Bibliotecas, Archivos y Museos, Centro de Investigaciones Diego Barros Arana, colección Sociedad y Cultura, 1993.

- «La lucha por la vivienda en tiempos de González Videla: Las experiencias de las poblaciones Los Nogales, Lo Zañartu y Luis Emilio Recabarren en Santiago de Chile, 1946-1947», Izquierdas.39 (2018): 1-33.

Romero, José Luis, Latinoamérica. Las ciudades y las ideas. Buenos Aires: Siglo Veintiuno Editores, 2010.

Sottorff, Carlos, La construcción ferroviaria y la transformación urbana y productiva de Santiago poniente, 1855-1897, Tesis Doctoral en Historia, Santiago de Chile: Departamento de Historia Universidad de Santiago de Chile, 2019.

Torres, Isabel, «Los conventillos en Santiago (1900-1930)», Cuadernos de Historia.6 (1986): 67-85.

Urbina, María Ximena. Los conventillos de Valparaíso, 1880- 1920: fisonomía y percepción de una vivienda popular urbana. Valparaíso: Ed. Universitarias de Valparaíso, 2002.

Valdivia, Verónica. Subversión, coerción y consenso. Creando el Chile del siglo XX (19181938), Santiago, LOM, 2017.

Varas, Augusto, «Los militares y la política en Chile: 1810-2015». Historia Política de Chile, 1810-2010. Tomo I. Eds. Iván Jaksic y Juan Luis Ossa. Santiago de Chile: Fondo de Cultura Económica y U. Adolfo Ibáñez, 2017. 